\title{
THE POSITION OF TOWNS IN DIGITAL CONSTRUCTION TECHNOLOGY ENVIRONMENT
}

\author{
DOI: 10.18485/arh_pt.2020.7.ch57
}

\author{
_ Velimir Stojanović \\ $\mathrm{PhD}$, Assistant Professor, University of Pristina in Kosovska Mitrovica, \\ Faculty of Technical Sciences, Kneza Mililosa No. 7, 38220 Kosovska \\ Mitrovica, ISO 3166-2: RS, velimir.stojanovic@pr.ac.rs
}

\section{ABSTRACT}

The position of towns in the traditional hierarchy was clear and defined. Their place and importance were defined by their structure, contents, and functions. Compared to cities, they had harmonized relationships that were more or less balanced and mutually beneficial. In towns, people lived in the conditions they provided, and migratory flows were a necessary consequence of the gravitational impacts of cities. Nowadays, city digitization has become a reality. The notion of the so-called digital or "smart city" encompasses, first and foremost, large and medium-sized cities, filling their urban parameters with the values given by computer science, from the planning process to the smallest streams and services in the processes of urban life. This "city in a city" or invisible city that constantly flows and manages the flows of everyday city needs has expanded into a global net they can no longer escape from. Cities need this as such globalization has given a whole new dimension to their existence and functioning. What about the position of towns? Are they necessarily sucked in and involved in this process of connection, or are they isolated and left to themselves? It would be logical to expect them to be part of one such global integration. But is it really so? By its very nature, a town has low resources and potentials, and it could be incorporated into a broader integrative process primarily from that point of view. Increasing these resources would necessarily mean that it would grow into a city, which could not be expected in most cases.

The first issue would lie in the very desire (ability) of a town to become a city. Abandoning such a desire would confirm the path to (self) isolation. The very position of a town could thus be found in proper assessing of its contents and fitting into the network of integrated cities and areas that is constantly growing and developing. Who could do this and in what way? A modern digital city has a large and well-developed power to manage its urban flow from the biggest issues to the smallest detail. That power, capacity, impact, and reach could be channeled to towns to provide them with the services they need.

KEYWORDS_ town, digital city, capacities, processes, integration

\section{INTRODUCTION}

The production of digital plans has become a reality in recent decades, not only in the experimental sphere but also in the sphere of effective implementation and daily practice. It is applicable at all levels, starting from the state and regional spatial plans themselves, through the level of cities and their urban regulations to the smallest administrative procedures such as issuing building permits and the like. The enabling information technology has evolved in phases over the years, going through periods of creating an IT "tool" (appropriate hardware and software), as well as through 
adapting and converting a classic stock of planning documents to a new digital format. This process has not been easy, it is still ongoing and commensurate with the issues it deals with. Digitization, as expected, encompassed primarily large cities and areas gravitating toward them, while smaller cities and towns were less concerned or not considered at all. This logically raises the question of whether (in due course) they will be dealt with at all, and what their place and position will be in the whole process. The question of small and medium-sized cities thus remains open and looks for possible solutions for their connection with the processes of overall digitization of planning, which will become more and more complex and content over time. The solutions to the involvement of small and medium-sized cities in this process, lie both in the cities themselves, and in the already developed system of new planning that could (should, must ...) include these cities and areas. The active participants managing these flows should recognize these needs in a timely manner, and use both, existing and future resources at their disposal, to avoid division (or, to a lesser extent, disproportion), into the areas involved in the process, and those that are not. Opinions on this come down to financialisation. Financialisation is hardly a new phenomenon in circuits of capital, the penetration of finance into various spheres of social and economic life speaks to its increasing dominance as a medium of socio-economic interactions (Lee et al., 2009). There are different definitions of the concept and meaning of the term financialization. Krippner defines it as a pattern of accumulation in which profit making occurs increasingly through financial channels rather than through trade and commodity production (Kripner, 2005).

\section{DIFFERENCES IN THE POSITION OF SMALL AND MEDIUM-SIZED CITIES IN RELATION TO MAJOR CITIES IN THE DIGITIZATION PLANNING PROCESS AND EXISTING PROBLEMS OF THE PROCESS}

Small and medium-sized cities have their traditional position in relation to large cities, and their position varies from case to case, depending on both spatial and temporal (historical) dimensions. The content of small and medium-sized cities was not necessarily linked to the development of large cities, and many of them developed separately, and more or less independently, in accordance with their resources. These resources were primarily based on location (geographic), then demographic, economic and then social and cultural. Connecting such cities to large cities was often not necessary, and usually amounted to the migratory movements of people from less developed areas to larger and more developed ones. The spatial-social relation was perceived as inevitable. The relations between spatial and social patterns are researched with a goal to established whether and how space influence into socio-economic processes through which the built environment is created and inverse way too. theories can use space syntax tools to explore How spatial patterns modify if objects in space are deployed in different ways, can be examine by using different methods like space syntax tools, analysis of the different functions and cultural models (Hillier, 1996). After all, there was also a review of environmental factors on the surroundings. The concept of the city is highlighted and its significance encouraged by way of ecology and information technologies, and saving the spatial resources by using modern technologies to reintegrate unused and abandoned spaces into the urban landscape (Ellin, 2006),

There were also small and medium-sized cities whose ties with large cities were tighter and more complex, but their numbers were smaller and their relationship and position were, and remained specific. In the current times of change, we cannot expect these traditional relationships to be maintained. When considering the future and the changes that the general digitization of spatial planning brings, it is necessary to impose at least three variants of the position of small and medium-sized cities within this process, and these variants would be the following:

- neglect of small and medium-sized cities in the framework of new forms of planning (at least until the technical and IT structure is raised to a higher and more developed level) This is shown in Figure 1. 


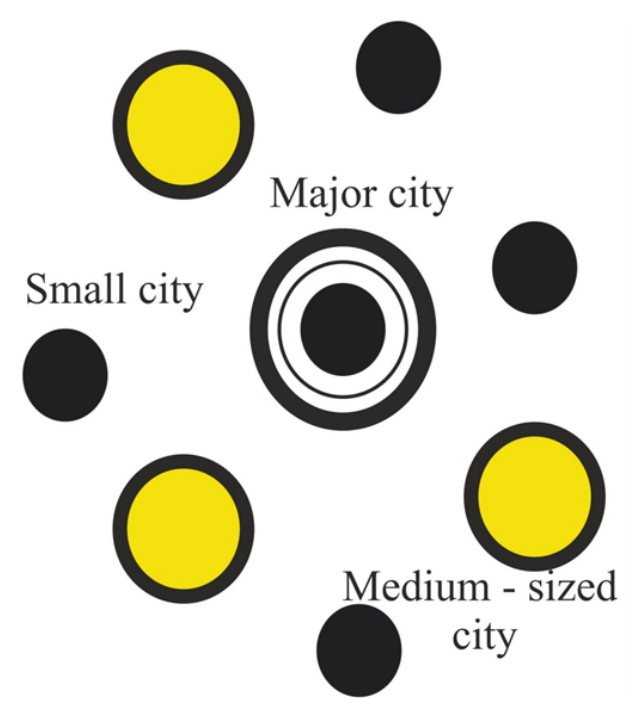

_ Figure 1: Cities without interconnections (Source by author)

- partial inclusion of small and medium-sized cities in new forms of planning, depending on the potentials, needs and interests of those who manage the planning

- continuous and synchronized inclusion of small and medium-sized cities in new forms of planning, based on an assessment of potentials, resources and needs, in order to obtain a comprehensive and unique planning concept and framework.

Considering that the digital planning system consists of a series of steps that attempt to make the planning complete, active and usable, both in the process of temporal development and in the current sense of present use, this is the area where the possibilities of answering all three mentioned variants should be sought. The question of the identity of these areas, the losses and the gains also becomes topical. The ways in which the changes will be implemented will decide whether these places will be pleasant to live in. It is important to note the shortcomings of a haphazard urbanization triggered by financialization, which eliminates the cultural aspect, and in the case of Serbia, creates a sense of non-place without authenticity identity, and identification, where man loses the sense of community and socialization, and where it is necessary to create an individual sense (Marc Augé, 1995). Identification determines the conditions of existence, including material and symbolic resources that are needed to maintain it (Hall, du Gay, 1996).

\section{DIGITAL PLANNING SYSTEM AND ITS TECHNICAL - FUNCTIONAL FEATURES}

Custom themes and data models (primarily graphic ones) are the basis of a digital planning system. A unique way of collecting this data (both old and new) is the hardest part of the job, both in creating databases, and in developing and creating hardware and software tools. While creating such systems, it seemed impossible to integrate all the plans and put them together in one place, without talking about any coherent analysis. In order for these systems to become balanced and stable, and to allow easy access to the use and utilization (reading) of the plans, both by expert and the general public, it was necessary to create adequate portals with modules and applications, standardize them, give them a special name and regulate them by legal regulations. The original digital plans, the system and the structure of their use, made at the end of the last century, were a major step up from the so-called "manual" design of plans, which in all environments were different, colorful and made according to the technical and legal norms and standards applicable to those environments. 
Subsequently, the new standards first required the development of spatial plans through the use of CAD or GIS software, and introduced a number of subsystems related to cartography, graphic layers, scales, symbols and other necessary contents of plan displays.

Both in the initial and ongoing digital planning system, there are a number of unresolved or partially solved problems. So, for example, there is the problem of coordinating systems (coordinate systems), prescribing data models in relation to them, evenly describing graphical data, and perhaps most, introducing new data obtained by experts, during their new work and research, as well as introducing new legal acts and laws enacted by the state and its institutions. Reorganization and domains thus become issues that are addressed by the decision-making system. For what concerns the management of built environment, and buildings in particular, the availability of an integrated system of knowledge is the basis for a smart assets management. The modelling of urban information at different level, from city-wide models to single building models, is the central idea of many smart city projects developed in different domains and it refers to internationally recognized data structures (BuildingSMART International, 2015) (Gröger et al. 2012). The dangers of disintegrating those decisions also arise as a possibility. Nevertheless, in developed countries existing buildings interest the majority of urban assets and the availability of integrated information able to describe the quality of the existing building stock requires city managers to face current problems associated with poor data quality, out-of-date databases and lack of interoperability between different sources (UN-GMM 2015).

Today we have reached a level of development in Serbia when the newly created digital plans (as well as the planning process itself) are available over the Internet, but this is not fully resolved and harmonized. Access through the Internet is not always the case, the plans given in this way are scattered on several web pages (their number can reach several hundreds) and the particular problem is the creation of plans in several sites where they are provided in different formats (pdf, jpg, tiff, dvf, etc.) Plans like these generally do not have the fully expected spatial reference, and sometimes do not need official verification. There is an urgent need for these plans to work in real time. Adaptive systems will be developed, able to detect the real time situation of built spaces, perceiving changes due internal uses and external conditions, planning alternatives responses, choosing the best action to undertake and monitoring the effect of such action (Mostashari et al.2011). Even miniature, local web portals are created, not so useful for wider use, that they hire a great deal of staff relative to their value, and spend a lot of financial means. This is shown in Figure 2.

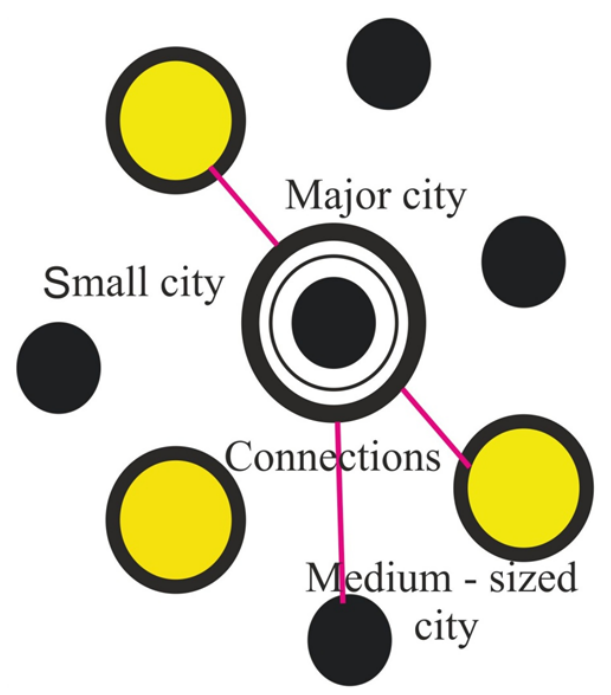

_ Figure 2: Cities with limited connections (Source by author) 
This puts a strain on both users and the institutions that need to use such data. Therefore, active participants are encouraged (forced) to prepare digital displays in a topologically orderly and technically clean manner in that process, so that the graphic and textual provisions of the different maps of the single spatial plan do not coincide, even if they were coincidence. The training of the personnel structure is imposed as a necessity. Methods differ, starting from development of amenities and special atmosphere in the city that attract creative people (Florida, 2002, Landry, 2000, Jacobs, 1969), clustering of companies (Scott, 2007), generation of job opportunities, or investment in educational and research institutions.

Digital planning from its higher levels necessarily goes down to the functional and usable levels of the lower species, and today it reaches levels of building permits (in a very short period of time) and monitoring and locating the occurrence of so-called "illegal construction", and disregard of spatial and urban plans in various locations and areas. The latter requires an IT segment that is valuable and necessary for all digital planning - and that is the interactive exchange of information through databases and their effective use in the prevention, control and elimination of this unwanted phenomenon, which has been widely spread in Serbia. This is significant, first of all, as it seeks to create a single, coherent, interactive and integrated system, which many see as the ultimate goal and success of digital planning and its ultimate validation and incorporation into new theory and practice. This is shown in Figure 3.

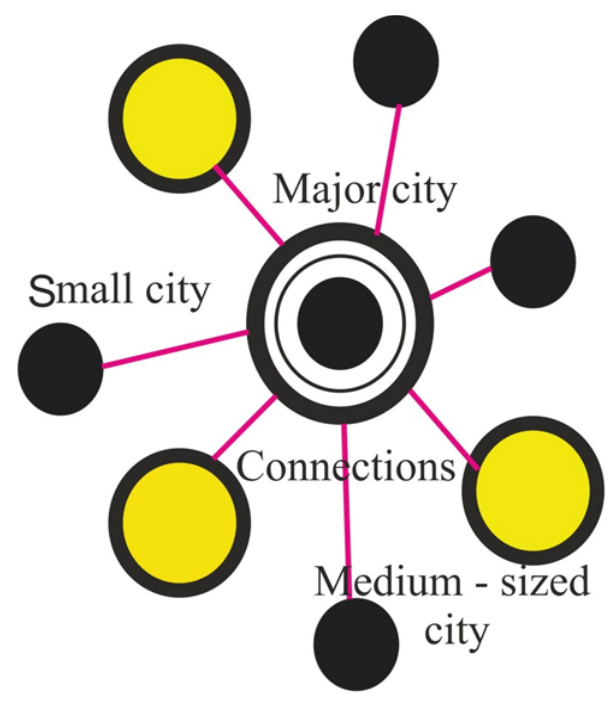

_ Figure 3: Cities with complete connections (Source by author)

The overall goal of globalization planning is thus indicated. Principal sites of cognitive-cultural economy are cities, especially top global cities (Scott, 2008). Expanding the ideas of work is for that purpose implied. Jane Jacobs (1984) connects city strength and position with its capability to produce ideas, or as she defines it, to conduct import-replacement cycle. Through import replacement cycle cities stop import, start producing for their needs and come to export their own products. Without this process cities are condemned on stagnation and decline. It is more important that cities have human potential for innovation, knowledge and creativity than having available natural resources and the newest infrastructure

Digital planning systems also use so-called locators, tools that can be linked to various applications inside or outside the system. They are important for adding data and spatial components to already written and formed databases, so that overall data can be displayed on the geoportal. In this way, for example, the aforementioned "illegal construction" objects can be located, entered in the 
appropriate registers and displayed as graphical representations on the geoportal, with appropriate alphanumeric data and related to the law and treatment of illegally constructed objects. All values of planning attributes become the destination of spatial and urban planning, and may even go up to the level of the project sector, in order to provide an instrument in the end, to get an answer as to what may (or may not) be built at any chosen location, how is it supposed to look like, if there are specific requirements for the implementation of the plan or project, and which body would be responsible for establishing those requirements. Association of multiple spheres of activity is thus expected. Krätke (2012) claims that scientific/technological occupations have the strongest impact on city economic growth and global urban positioning, followed by artistic occupations, basing his claims on the research of employment in different sectors. The results of such an association would quickly become visible. Most of these strategies are based on theories and principles established by Landry (2000) and Florida (2002). Urban programs based on Landry's work are putting emphasis on local governance creativity, creative leaders of the city and engaging citizens in this process. They use local cultural potentials and identity, evolve it to create broadly recognizable image, a brand of the city. Digital planning processes thus become the physical framework of the country they cover, and are being implemented on, which technically means that topics within a single process (layer) cannot overlap. Every part or point on the land can only have one predefined purpose (for example, residential, industrial, agriciltural, etc.) and only one set of enforcement rules. This kind of existence and the way digital plans work, will be crucial (destinal) for the treatment of small and medium-sized cities, integrating them with larger and more developed environments, and ultimately placing them in a comprehensive digital spatial planning system. All this would be based on the improved economic footing that the environment provides. If the city governance wants to keep the capacity for knowledge and innovation it needs to take careful small interventions that will protect original groups. Too high institutionalization will drive away investors and suppress alternative character. Informal and smaller art organizations are more important than flagship cultural institutions for social networking (Currid, 2007). In the new economy it is necessary to link scientific and technological innovation production with local artistic and cultural creativity, since only by joint appearance they contribute to enhancement of city cognitive-cultural economy (Krätke, 2012).

\section{ANALYSIS OF SMALL AND MEDIUM-SIZED CITIES AND THEIR VALORIZATION IN A NEW, DIG- ITAL PLANNING SYSTEM}

The treatment of each small and medium-sized city would begin with an analysis of its current resources. First the geographical position and topological characteristics, then the demographic situation and then the economic capacities and social image at its disposal. It would be then necessary to determine the required economic means to begin the planned digitization of area. Connections with major cities would not be a planning priority at the outset of the work, since the idea of digital planning is in principle tied to wider areas, up to country (state) level, and would (with respect to analysis) be concerned with assessing whether such a city should undergo digital spatial plans at any given time. From this, we draw the conclusion that the decision to digitize is primarily of a technical and economic nature, and not political or otherwise, and that it depends on the above mentioned conditions. There are also broader and more detailed ideas about this. For example, the comprehensive definition by Laguerre describes the digital city as 'a set of virtual practices or repertoires that are undertaken in a sustainable manner by individual residents and groups of a particular city for the purpose of interacting, simulating, explaining, reinforcing, monitoring, neutralizing, criminalizing, expanding (locally or globally), processing, transacting, or undermining any political, social, economic, religious or communicational aspect of the daily activities of the urban community'(Laguerre, 2005:1). Of course, it is a desire in modern societies to encompass as much of the area/space as possible, by developing digital plans, and refining them at all levels enumerated. Experience in perceiving digital cities is demanding. The contemporary cities, pervaded by ICT networks, generate a new experience of physical locations. 
The importance of data has been recognized in different aspects of urban life, adding a new dimension of spatial perception in which a concentration of information is more important than a number of inhabitants (Vidler, 1992), Urban media, as defined by (de Waal, 2014), could be used as so-called 'experience markers' and/or 'territory devices', recording events in the space and/or influencing the experience of a place. At that moment, a turning point may arise - which fatefully determines the relationship of small and medium-sized cities to large centers. It is sufficient enough that one product of the analysis does not show that, at this point in time it is necessary to start making digital plans for a specific area, and to abandon them. Especially if it is found that more than one product of analysis is in support of it, or it is found that there is not enough appropriate economic resources to access the business. Then the fate of a small or medium-sized city tends to the first variant mentioned in the previous chapter - isolation and neglect. This is not the case when decisions on the development of digital plans are made from a center (s) that has technical and economic measures. A different course of events would be when small and medium-sized cities themselves had the resources and were able, and in position, to make decisions independently, and on their own, but this is rarely the case.

The products of the analysis of small and medium-sized places may also be such that they can be partially developed for digital plans, which would in particular be applied to certain values derived from the analysis, to which the development of digital plans would then be tied. Such partial digital planning would cover only one part of a complex set of digital space planning treatments, while the rest would be left to some other times and opportunities. The relationship of the partial and the complete is not unsolvable. The role of information networks would be to improve urban functionality by increasing the efficiency and complexity of information exchange, without necessity to adjust to existing spatial modules. (Mitchell, 2000) also proposes a digital - 'smart' upgrading of existing spatial structures, within an overall intelligent adaptation and automated personalization introduced by the concept of e-topia.

To put it simply, it would be like saying "all that you do not have to do today, leave it for tomorrow." It can be seen that this approach and such solution (s) is not ideal, and that in most cases it is not good for anyone but is used and applied in practice. If such plans were to be extended and established, this would not be good for the digital plan as a whole, since it would be inconsistent with many shortcomings and unfulfilled goals. However, if applied to a number of examples, it would lead to the second variant mentioned - the partial inclusion of small and medium-sized cities in new forms of planning, depending on the capabilities, needs and interests of those who manage that planning. The most successful, and therefore, the best implementation and realization of digital plans for small and medium-sized cities would be the one in which prior analysis (analyzes), supported by specific economic means and technical potentials would fully (or to the greatest extent), cover and process the space, and accommodate it into a connected network of the digital planning structure of the country, thus providing them with the necessary connections with large places and centers. This is undoubtedly the desire of those involved in digital planning, but unfortunately this desire is not always in line with the possibilities. This does not mean that this wish could not be fulfilled. According to (Landry, 2005), the foundation of the creative city is influenced by several factors: personal qualities, will and leadership, human diversity and access to varied talent, organizational culture, local identity, urban spaces and facilities, networking dynamics.

However, the most important among them are political will and appropriate organizational culture which means that both governmental and other stakeholders should recognize the need for creative city - as a model which stimulates and generates new ideas and approaches. Simultaneously, the existence of a digital platform, as an interface between stakeholders, has already become a necessity in developing and exchanging knowledge, especially in the area of climate/environmental awareness. In the future, this approach is expected to be dominant over the previous two options in in Serbia as well, regardless of all the limitations and difficulties that exist in it. A certain order of procedures would go that route. According to (Healey, 1997), collaborative planning integrates soft and hard infrastructure through procedures and protocols of communication that enable wider participation and representation in decision-making process. 
As far as the planning practice referred to the position of the towns concerned, we can say that is refers to the development of a digital way of planning and all those technological recourses that this technology requires. It is complete change in the way of planning from legal administrative procedures to the use of permanent use of new technology that the institutions that would deal with it would have. This, of course, implies a change in the way employees of these institutions work an a change in the habits of service users.

All of this does not, of course, apply to cases where other factors are deciding in the process of digitizing plans of area and place, such as political decisions made outside the consultation and consent of the profession, particular economic reasons, and even resistance and misunderstanding within small and medium-sized cities when it comes to these activities.

\section{CONCLUSION}

The position of small and medium-sized cities is not predetermined in this digital planning system as it was (or would be) in the old system, or in the inherited traditional relationships. All their positions and places depend primarily on the technical - economic means and capabilities managed by the state, and the institutions authorized therein, and to a lesser extent, on the ability and capability of small and medium - sized cities to do so themselves. Therefore, their new connection with major cities, regions and areas, depend on it. Creating new digital plans thus becomes a new condition for better positioning and better connectivity, which was not the case before. This condition does not have to be used, or it does not have to be exploited to the end, but it becomes a testament to how much new technology, new approaches and new practices are changing the old conditions, and paving the way for new solutions and a new spatial planning hierarchy. The best change would happen in terms of removing the old system and organizing city planning and replacing it with a new one. The planning practice would be significantly different in essence and form. Connecting towns to all levels of urbanizations an beyond would be more meaningful, complex and larger. Towns would no longer look like isolated planning units or parts of semi - planned spaces but will be integrated into stat - level planning process. This would primarily refer to the connections of large, medium and small cities. This will be greatest contribution that the position of towns in the digital planning process makes to the practice of planning.

When this is so set, new developments in the economic, social and cultural system, structure and function of place and area or space, slowly begin to emerge. This would prove that digital planning is a major asset in the development of small and medium-sized cities, and their path to a better and more harmonious way of living in them. Small and medium-sized cities will not become larger (though it is not excluded), but their position will become an integral part of the general structure of planning reality, where many of their problems and issues will be solved in a much faster and better way.

\section{REFERENCES}

_ Augé, Marc. 1995. Non-PlacesIntroduction to an Anthropology of Supermodernity: Verso.

_ Currid, Elizabeth. 2007. The Warhol Economy: How Fashion, Art and Music Drive. New York City. Princeton: Princeton University Press.

_ de Waal, Martijn. 2014. The City as Interface. Rotterdam: nai010 publishers

_ Ellin, Nan. 2006. Integral Urbanism. New York: Routledge.

_ Gröger, G. et al., 2012. City Geography Markup Language ( CityGML ): En- coding Standard.

_ Hall, Stuart, and Paul du Gay. 1996. Questions of Cultural Identity: SAGE Publications Ldt

- Healey, Patsy. 1997. Collaborative Planning: Shaping Places in Fragmented Societies. London: Macmillian Press.

_ Hillier, Bill. 1996. Space is the Machine, A Configurational Theory of Architecture. Cambridge: Cam- 
bridge University Press.

- Jacobs, Jane. 1969. The Economy of Cities. New York: Random House.

- Jacobs, Jane. 1984. Cities and the Wealth of Nations. New York: Random House.

- Krippner, Greta. 2005. "The Financialization of the American Economy." Socio-Economic Review, no.

3: 174 .

- Krätke, Stefan. 2012. The Creative Capital of Cities. Interactive Knowledge Creation and the Urbanization Economies of Innovation. Malden and Oxford: Wiley-Blackwell.

- Landry, Charles. 2000. Creative City: A Toolkit for Urban Innovators. London: Earthscan Publications.

- Landry, Charles. 2005. The Creative City: A Toolkit for Urban Innovators. London: Earthscan Publications..

- Laguerre, Michel S. 2005.The Digital City - The American Metropolis and Information Technology. Berkeley, LA: University of California Press.

- Lee, Roger. 2009. "The remit of financial geography-before and after the crisis." Journal of Economic Geography, no. 9: 723-747.

- Mostashari, A. et al., 2011. "Cognitive Cities and Intelligent Urban Governance". Network Industries Quarterly, no 13:.4-7.

- Mitchel, William J. 2000.E-topia: Urban life, Jim - But not as we know it, London, Cambridge, MA: MIT Press.

- Scott, Allen. 2008. Social economy of the metropolis: Cognitive-cultural capitalism and the global resurgence of cities. Oxford, New York: Oxford University Press.

_ UN-GMM, 2015. "Future Trends in geospatial information management : the five to ten year vision SECOND EDITION" For review by United Nations Committee of Experts on Global Geospatial Information Management:

- Vidler, Anthony. 1992. The architectural uncanny: Essays in the modern unhomely. Cambridge, MA: MIT Press. 